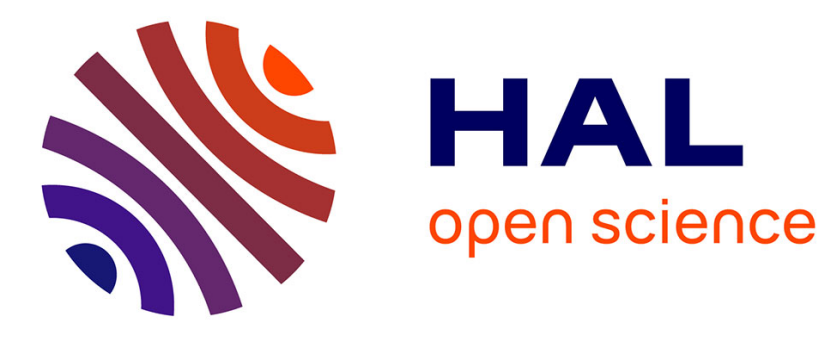

\title{
Ionic liquid-based uranium( vi ) extraction with malonamide extractant: cation exchange vs. neutral extraction
}

Clotilde Gaillard, Maria Yu Boltoeva, Isabelle Billard, Sylvia Georg, Valérie Mazan, Ali Ouadi

\section{To cite this version:}

Clotilde Gaillard, Maria Yu Boltoeva, Isabelle Billard, Sylvia Georg, Valérie Mazan, et al.. Ionic liquidbased uranium( vi ) extraction with malonamide extractant: cation exchange vs. neutral extraction. RSC Advances, 2016, 6 (74), pp.70141-70151. 10.1039/c6ra11345a . hal-02271345

\section{HAL Id: hal-02271345 \\ https://hal.science/hal-02271345}

Submitted on 26 Aug 2019

HAL is a multi-disciplinary open access archive for the deposit and dissemination of scientific research documents, whether they are published or not. The documents may come from teaching and research institutions in France or abroad, or from public or private research centers.
L'archive ouverte pluridisciplinaire HAL, est destinée au dépôt et à la diffusion de documents scientifiques de niveau recherche, publiés ou non, émanant des établissements d'enseignement et de recherche français ou étrangers, des laboratoires publics ou privés. 


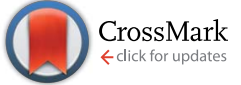

Cite this: RSC Adv., 2016, 6, 70141

Received 2nd May 2016

Accepted 11th July 2016

DOI: 10.1039/c6ra11345a

www.rsc.org/advances

\title{
Ionic liquid-based uranium(vi) extraction with malonamide extractant: cation exchange vs. neutral extraction $\uparrow$
}

\author{
Clotilde Gaillard, ${ }^{\text {aa }}$ Maria Boltoeva, ${ }^{\text {bc }}$ Isabelle Billard, ${ }^{\text {de }}$ Sylvia Georg, ${ }^{\text {bc }}$ Valérie Mazan ${ }^{\text {bc }}$ \\ and Ali Ouadibc
}

\begin{abstract}
We present new insights into the extraction of uranium(vi) from a nitric acid aqueous phase into 1butyl-3-methylimidazolium bis(trifluoromethanesulfonyl)imide ionic liquid $\left(\left[\mathrm{C}_{4} \mathrm{mim}\right]\left[\mathrm{Tf}_{2} \mathrm{~N}\right]\right)$ using a malonamide extractant, namely $N, N^{\prime}$-dimethyl- $N, N^{\prime}$-dibutylmalonamide (DMDBMA). UV-vis absorption spectrophotometry and extended X-ray absorption fine structure (EXAFS) experiments have been carried out on the extracted phases and new extraction data were used in order to model the mechanism lying behind the $U(\mathrm{VI})$ extraction. We show that two different uranyl species are involved, as a function of the aqueous nitric acid concentration: the cation $\cup_{2}(\mathrm{DMDBMA})_{x}{ }^{2+}(2 \leq x \leq 3)$ at low acid concentration, and the neutral $\mathrm{UO}_{2}\left(\mathrm{NO}_{3}\right)_{2}(\mathrm{DMDBMA})$ at high acid concentration. The former is extracted by exchange with 2 protons, while the latter is co-extracted with a $\mathrm{HNO}_{3}$ molecule. We show that the uranium extraction is performed without the direct help of IL ions, although the latter pollute noticeably the aqueous phase.
\end{abstract}

\section{Introduction}

Ionic liquids (IL) are a well-known class of solvents composed entirely of cations and anions. The use of hydrophobic ILs in the replacement of traditional organic solvents for the metal ion extraction has been widely studied over the last few years, showing the ability of these unusual solvents to improve the efficiency and/or the selectivity of the metal ion separation in comparison with traditional organic solvents. ${ }^{1-5}$ The hydrophobicity of the studied IL is usually driven by the $\mathrm{Tf}_{2} \mathrm{~N}^{-}$anions $\left(\mathrm{Tf}_{2} \mathrm{~N}\right.$ being bis(trifluoromethanesulfonyl)imide), while the cationic part is composed of imidazolium $\mathrm{C}_{n} \mathrm{mim}^{+}$, pyridinium or tetraalkylammonium based patterns. In molecular solvents, the metallic species extracted with the help of an organic extractant molecule are neutral solvates and ion-pairs. The use of IL complicates the extraction process. According to the nature of the IL ions, the extracting molecule and the aqueous phase composition (nature and concentration of the mineral acid), the extraction may be performed via an ion-exchange process, neutral coextraction or a more "traditional" neutral

${ }^{a}$ Institut de Physique Nucléaire de Lyon, Université de Lyon, CNRS-IN2P3, 69622 Villeurbanne Cedex, France. E-mail: gaillard@ipnl.in2p3.fr

${ }^{b}$ Université de Strasbourg, IPHC, 23 rue du Loss, 67037 Strasbourg, France ${ }^{c}$ CNRS, UMR 7178, 67037 Strasbourg, France

${ }^{d}$ Univ. Grenoble Alpes, LEPMI, 38000 Grenoble, France

${ }^{e}$ CNRS, LEPMI, 38000 Grenoble, France

$\dagger$ Electronic supplementary information (ESI) available. See DOI: 10.1039/c6ra11345a solvation. ${ }^{6}$ The former mechanism is often presented as a major drawback for a foreseen IL use for industry as the exchange may be performed with IL ions and entails a pollution of the aqueous phase. As a consequence, researches are made in order to reduce this phenomenon, ${ }^{7,8}$ for instance by increasing the IL hydrophobicity by using cations with long alkyl chains, like $\mathrm{C}_{8} \mathrm{mim}^{+}$or $\mathrm{C}_{10} \mathrm{mim}^{+}$, or highly hydrophobic binary extractants. ${ }^{9}$ However, this often goes with a drop of the extraction efficiency. ${ }^{\mathbf{1 0 - 1 3}}$ Moreover, the inherent solubility of the ionic liquid in the acidic aqueous phase by contact during the extraction process is also to be considered, as it was shown to depend on the nature of the IL but also on the nature and concentration of the acid. ${ }^{14,15}$

The partitioning of actinides from the spent nuclear fuel is made by hydrometallurgical methods based on successive liquid-liquid extraction processes from a nitric aqueous phase. Many studies have been made on the possible use of IL in such processes to replace the organic solvents used nowadays. ${ }^{11,14,16-24}$ Among possible extractants, malonamides allow a selective separation of actinides over fission products, have the advantage to be completely incinerable (necessary for nuclear waste management) and to display a large variety of structures, owing to the flexibility of their chemical backbone. ${ }^{25}$ In molecular solvents, the extraction of uranium(vi) from nitric acid phase is formally made via the formation of a neutral solvate $\mathrm{UO}_{2}\left(\mathrm{NO}_{3}\right)_{2} \mathrm{~L}^{26,27}$ But the formation of the protonic form of amides is not negligible at high acidic conditions. Also, malonamides have a large affinity for $\mathrm{HNO}_{3}$ which leads to the extraction of non-dissociated acid in the organic phase by the 
formation of $\mathrm{L}_{x}\left(\mathrm{HNO}_{3}\right)_{y}$ species, even at low acid concentration..$^{\mathbf{2 8} 29}$ As a consequence, it was suggested that the separation of uranium at high $\mathrm{HNO}_{3}$ loading goes with the co-extraction of a nitric acid molecule, and thus, to the extraction of $\mathrm{UO}_{2}\left(\mathrm{NO}_{3}\right)_{2}(\mathrm{~L}) \mathrm{HNO}_{3}$ (ref. 30 and 31) or $\mathrm{UO}_{2}\left(\mathrm{NO}_{3}\right)_{2}(\mathrm{~L}) \mathrm{HNO}_{3} \mathrm{~L}$ species. ${ }^{32}$ Several authors have replaced the molecular solvent by the $\left[\mathrm{C}_{4} \mathrm{mim}\right]\left[\mathrm{Tf}_{2} \mathrm{~N}\right]$ ionic liquid to study the extraction of actinides by malonamides. Rout et al. ${ }^{12}$ performed the extraction of $\mathrm{Pu}(\mathrm{IV}), \mathrm{Am}(\mathrm{III})$ and $\mathrm{U}(\mathrm{vI})$ by the $N, N$-dimethyl- $N, N$-dioctyl2-(2-hexyloxyethyl)malonamide ligand (DMDOHEMA). In the case of uranium they report a decrease of the distribution coefficient as a function of the $\mathrm{HNO}_{3}$ concentration in the 0.5-8 $M$ range, and postulate the extraction of a cationic species containing two ligands in the whole acidic range. Patil et al. ${ }^{33}$ used two different malonamide extractants, including DMDOHEMA, to extract uranium(vi) in an $\left[\mathrm{C}_{4} \mathrm{mim}\right]\left[\mathrm{Tf}_{2} \mathrm{~N}\right]$ IL phase, below $3 \mathrm{M} \mathrm{HNO}_{3}$. They show two trends in the process as the nitric acid concentration increases: for $\left[\mathrm{HNO}_{3}\right]<0.1 \mathrm{M}$, a strong increase of the distribution coefficient is observed, which is ascribed by the authors to an IL cation exchange mechanism, while $D_{\mathrm{U}}$ decreases between 0.1 and $3 \mathrm{M} \mathrm{HNO}_{3}$.

In a previous work, ${ }^{34}$ we have focused our attention on the extraction of uranium(vI) with malonamide extractants in the IL $\left[\mathrm{C}_{4} \mathrm{mim}\right]\left[\mathrm{Tf}_{2} \mathrm{~N}\right]$, comparing the extraction efficiency between a single malonamide molecule $\left(N, N^{\prime}\right.$-dimethyl- $N, N^{\prime}$-dibutylmalonamide, so called DMDBMA) and a malonamidefunctionalized ionic liquid. Using the DMDBMA molecule as extractant, we evidenced a boomerang-shape curve of extraction with a turning point at $2 \mathrm{M} \mathrm{HNO}_{3}$. We proposed that the extraction of $\mathrm{U}(\mathrm{vI})$ with DMDBMA at low nitric acid concentration is performed by a cation exchange between $\mathrm{UO}_{2}{ }^{2+}$ and $2 \mathrm{H}^{+}$, while it would occur at high $\mathrm{HNO}_{3}$ concentration by an anionexchange between $\mathrm{UO}_{2}\left(\mathrm{NO}_{3}\right)_{3}{ }^{-}$and one $\mathrm{Tf}_{2} \mathrm{~N}^{-}$. This assumption was based on the variation of the uranium distribution coefficient $D_{\mathrm{U}}$ as a function of $\left[\mathrm{HNO}_{3}\right]$ or [DMDBMA], and from the impact of the aqueous $\mathrm{C}_{4} \mathrm{mim}^{+}$and $\mathrm{Tf}_{2} \mathrm{~N}^{-}$concentrations on the extraction efficiency. The present work gives new insights in this system. In particular, the characterization of the extracted species was done by UV-vis spectroscopy and X-ray absorption spectroscopy (EXAFS), showing results that are not in agreement with the extracted anionic species postulated at high $\mathrm{HNO}_{3}$ concentration. New extraction data were collected, in order to take into account the solubility of the ionic liquid ions in the aqueous phase and of the nitric acid in the IL phase. Taking advantage of this complete data set, we propose a refined model for the extraction of uranium(vi) in $\left[\mathrm{C}_{4} \mathrm{mim}\right]$ $\left[\mathrm{Tf}_{2} \mathrm{~N}\right]$ with DMDBMA. In particular, we show that the uranium extraction is performed without the direct help of IL ions, although the latter pollute noticeably the aqueous phase.

\section{Experimental section}

\subsection{Chemicals}

All chemical reagents were used as received without any further purification. 1-Butyl-3-methylimidazolium bis(trifluoromethanesulfonyl)imide (high purity grade $99.5 \%$, hereinafter indicated as $\left[\mathrm{C}_{4} \mathrm{mim}\right]\left[\mathrm{Tf}_{2} \mathrm{~N}\right]$ ) was purchased from
Solvionic (Toulouse, France). The syntheses of $\mathrm{UO}_{2}\left(\mathrm{Tf}_{2} \mathrm{~N}\right)_{2}$ and $\left[\mathrm{C}_{4} \mathrm{mim}\right]\left[\mathrm{NO}_{3}\right]$ have been reported elsewhere. ${ }^{35} N, N^{\prime}$-Dimethyl$N, N^{\prime}$-dibutylmalonamide (DMDBMA) was prepared and characterized according to the published method. ${ }^{34}$ The other chemical reagents used, 1,2-dichloroethane, concentrated nitric acid, sodium trifluoroacetate, sodium citrate, deuterated nitric acid and deuterium oxide were of analytical grade. Deionized water from an Elga ${ }^{\circledR}$ purification system of resistivity 18.2 $\mathrm{M} \Omega$ $\mathrm{cm}$ was used for solution preparations and dilutions.

\subsection{Sample preparation}

The highly hygroscopic uranium salt $\mathrm{UO}_{2}\left(\mathrm{Tf}_{2} \mathrm{~N}\right)_{2}$ and the ionic liquids $\left[\mathrm{C}_{4} \mathrm{mim}\right]\left[\mathrm{NO}_{3}\right]$ and $\left[\mathrm{C}_{4} \mathrm{mim}\right]\left[\mathrm{Tf}_{2} \mathrm{~N}\right]$ were dried prior to use under vacuum at $60 \pm 1{ }^{\circ} \mathrm{C}$ for two hours and then for one hour at ambient temperature. ${ }^{35}$

Two sets of samples were prepared in order to measure the final aqueous concentration of $\mathrm{C}_{4} \mathrm{mim}^{+}$and $\mathrm{Tf}_{2} \mathrm{~N}^{-}$as a function of the initial nitric acid concentration at $[\mathrm{DMDBMA}]_{\mathrm{IL}}=50 \mathrm{mM}$, and as a function of the DMDBMA concentration at two nitric acid concentrations $\left(\left[\mathrm{HNO}_{3}\right]_{\mathrm{aq}, \text { init }}=0.45 \mathrm{M}\right.$ and $\left.4.51 \mathrm{M}\right)$. Equal volumes of organic and aqueous phases were used (typically 0.5 $\mathrm{mL}$ ). The organic phase was prepared by dissolving weighted amount of DMDBMA in neat $\left[\mathrm{C}_{4} \mathrm{mim}\right]\left[\mathrm{Tf}_{2} \mathrm{~N}\right]$. The aqueous phases were obtained by dilution of concentrated $\mathrm{HNO}_{3}$ or $\mathrm{DNO}_{3}$ in the case of further NMR measurements. We assume a similar behavior (i.e. a small isotopic effect) between the deuterated $\mathrm{DNO}_{3}$ and non-deuterated $\mathrm{HNO}_{3}$ acids. After mixing in $2.0 \mathrm{~mL}$ Eppendorf tubes, the biphasic system was shaken mechanically (VXR basic Vibrax, IKA) at $1200 \mathrm{rpm}$ for three hours at room temperature $\left(20 \pm 1{ }^{\circ} \mathrm{C}\right)$ and then separated by centrifuging at $4000 \mathrm{rpm}$ for two minutes (Micro Star 12, VWR). Then, the aliquots of equilibrium aqueous phase were taken for further analysis.

The composition of samples analyzed by EXAFS and UV-vis spectroscopy is given in Table 1 . The first set was obtained by dissolving in neat $\left[\mathrm{C}_{4} \mathrm{mim}\right]\left[\mathrm{Tf}_{2} \mathrm{~N}\right]$ weighted quantities of $\mathrm{UO}_{2}\left(\mathrm{Tf}_{2} \mathrm{~N}\right)_{2}$, DMDBMA and/or $\left[\mathrm{C}_{4} \mathrm{mim}\right]\left[\mathrm{NO}_{3}\right]$. The final water content in those solutions was measured after EXAFS measurements by coulometric technique (Karl-Fischer titration, Mettler Toledo DL 32) and found below $100 \mathrm{ppm}$. The second set of IL samples was obtained by extraction of uranium(vI) with 0.3 M DMDBMA from aqueous nitric acid solutions $\left(\left[\mathrm{HNO}_{3}\right]=\right.$ 0.5 $\mathrm{M}$ and 6.3 M), using the experimental protocol described above. Prior to $\mathrm{U}(\mathrm{vI})$ solvent extraction, the organic and aqueous phases were pre-equilibrated for three hours and then an aliquot of $1 \mathrm{M} \mathrm{UO}_{2}\left(\mathrm{Tf}_{2} \mathrm{~N}\right)_{2}$ in $1 \mathrm{M} \mathrm{HNO}_{3}$ was added to the aqueous phase to reach an initial $\mathrm{U}(\mathrm{vI})$ concentration of 0.006 M. For comparison purpose, a sample obtained by extraction of uranyl from 3.3 $\mathrm{M} \mathrm{HNO}_{3}$ towards 1,2-dichloroethane (DCE) with the help of 0.3 M DMDBMA was also prepared. It contains the neutral complex $\mathrm{UO}_{2}\left(\mathrm{NO}_{3}\right)_{2} \cdot$ DMDBMA. $^{32}$

\subsection{Technical procedures}

After extraction, the aqueous concentrations of IL ions were measured by the NMR technique as reported in detail elsewhere. ${ }^{15}$ Briefly, an aliquot of the internal standard solution was 
Table 1 Composition of IL samples analyzed by EXAFS and UV-vis spectroscopy. $\left[\mathrm{UO}_{2}{ }^{2+}\right]=0.01 \mathrm{M}$ for samples made by salt dissolution in $\left[\mathrm{C}_{4} \mathrm{mim}\right]\left[\mathrm{Tf}_{2} \mathrm{~N}\right]$, and $\left[\mathrm{UO}_{2}{ }^{2+}\right]_{\mathrm{aq}, \text { init }}=0.006 \mathrm{M}$ for extracted samples. Nitrates were dissolved as the $\left[\mathrm{C}_{4} \mathrm{mim}\right]\left[\mathrm{NO}_{3}\right]$ salt in the IL

Samples made by salt dissolution in $\left[\mathrm{C}_{4} \mathrm{mim}\right]\left[\mathrm{Tf}_{2} \mathrm{~N}\right]$

\begin{tabular}{|c|c|c|c|c|}
\hline Sample ID & {$\left[\mathrm{NO}_{3}^{-}\right](\mathrm{M})$} & [DMDBMA] (M) & {$\left[\mathrm{UO}_{2}{ }^{2+}\right] /\left[\mathrm{NO}_{3}{ }^{-}\right] /[\mathrm{DMDBMA}]$} & Speciation obtained by EXAFS ( $c f$. Table S1) \\
\hline S1_0_1 & 0 & 0.01 & $1 / 0 / 1$ & {$\left[\mathrm{UO}_{2}(\mathrm{DMDBMA})\right]^{2+}$} \\
\hline S1_0_2 & 0 & 0.02 & $1 / 0 / 2$ & {$\left[\mathrm{UO}_{2}(\mathrm{DMDBMA})_{2}\right]^{2+}$} \\
\hline S1_0_4 & 0 & 0.04 & $1 / 0 / 4$ & {$\left[\mathrm{UO}_{2}(\mathrm{DMDBMA})_{3}\right]^{2+}$} \\
\hline S1_1_2 & 0.01 & 0.02 & $1 / 1 / 2$ & {$\left[\mathrm{UO}_{2}\left(\mathrm{NO}_{3}\right)(\mathrm{DMDBMA})_{2}\right]^{+}$} \\
\hline S1_2_2 & 0.02 & 0.02 & $1 / 2 / 2$ & {$\left[\mathrm{UO}_{2}\left(\mathrm{NO}_{3}\right)(\mathrm{DMDBMA})_{2}\right]^{+}+\mathrm{UO}_{2}\left(\mathrm{NO}_{3}\right)_{2}(\mathrm{DMDBMA})$} \\
\hline
\end{tabular}

Extracted samples

\begin{tabular}{|c|c|c|c|}
\hline & {$\left[\mathrm{HNO}_{3}\right]_{\mathrm{aq}, \text { init }}(\mathrm{M})$} & [DMDBMA] (M) & $\begin{array}{l}\text { Speciation obtained by } \\
\text { EXAFS ( } c f . \text { Table S1) }\end{array}$ \\
\hline Sample A & 0.6 & 0.3 & {$\left[\mathrm{UO}_{2}(\mathrm{DMDBMA})_{3}\right]^{2+}$} \\
\hline Sample B & 6.3 & 0.3 & $\mathrm{UO}_{2}\left(\mathrm{NO}_{3}\right)_{2} \cdot \mathrm{DMDBMA}$ \\
\hline 1,2-Dichloroethane (DCE) & 3.3 & 0.3 & $\mathrm{UO}_{2}\left(\mathrm{NO}_{3}\right)_{2} \cdot \mathrm{DMDBMA}$ \\
\hline
\end{tabular}

added to an aliquot of the aqueous phase containing IL ions and then the total volume was adjusted with deuterium oxide. Sodium citrate and sodium trifluoroacetate were used as internal standards for ${ }^{1} \mathrm{H}$ and ${ }^{19} \mathrm{~F}$ quantitative NMR measurements, respectively. NMR spectra were acquired using a Bruker Avance-I $300 \mathrm{MHz}$ spectrometer at $298 \mathrm{~K}$.

The U(vi) concentration in stock and work solutions was determined by inductively coupled plasma mass-spectroscopy (ICP-MS, Agilent 7500i) after dilution to the concentration suitable for measurements by 2 vol\% nitric acid solution, which contains $10 \mu \mathrm{g} \mathrm{L}^{-1} \mathrm{Tl}$ as an internal standard.

UV-vis absorption spectra have been recorded at room temperature by a Varian Cary 100 spectrophotometer using a quartz cell (optical path length $1 \mathrm{~cm}$ ) with neat $\left[\mathrm{C}_{4} \mathrm{mim}\right]\left[\mathrm{Tf}_{2} \mathrm{~N}\right]$ as reference or pure DCE, accordingly.

EXAFS measurements were carried out at the ROBL beamline, ESRF (Grenoble, France) at ambient temperature, using a double crystal $\mathrm{Si}(111)$ monochromator. Analysis were made at the $\mathrm{U} \mathrm{L}_{\mathrm{III}}(17166 \mathrm{eV})$ edge in fluorescence mode using a 13element germanium detector. The monochromator energy was calibrated by an yttrium metal foil (17 $038 \mathrm{eV})$. After their deadtime correction, data were extracted using ATHENA software ${ }^{36}$ and their analysis was carried out with the FEFFIT code,${ }^{37}$ using phase and backscattering amplitude functions generated with the FEFF 8.1 code. $^{38}$ Fits of the Fourier transform (FT) $k^{3}$ weighted EXAFS data to the EXAFS equation were performed in the R-space between 1 and $4.3 \AA$. The $k$-range used was 3.0-16 $\AA^{-1}$. The amplitude reduction factor $\left({S_{0}}^{2}\right)$ was held constant to 1 for all fits. The shift in the threshold energy $\left(E_{0}\right)$ was allowed to vary as a global parameter for all atoms. In all fits, the coordination number of the uranyl axial oxygen atoms $\left(\mathrm{O}_{\mathrm{ax}}\right)$ was held constant at two. The multiple scattering paths of the axial oxygens were included in the fit by constraining its effective path-length to twice the values of the corresponding $\mathrm{U}-\mathrm{O}_{\mathrm{ax}}$ distance. The presence of DMDBMA molecules in the coordination sphere entails the presence of two strong multiple scattering contributions that were taken into account without adding any fitted parameters $\left(N, \sigma^{2}\right.$ and $R$ were linked to values obtained for the single scattering contribution $\mathrm{U}-\mathrm{C}$ ). The same procedure on multiple scattering contributions arising from nitrate groups was applied.

\subsection{Fittings}

The different chemical models examined in this work have been turned into a set of mathematical equations, based on the mass action law, mass balance for $\mathrm{U}(\mathrm{vI})$ and charge balance in the aqueous phase. As already detailed in our previous works, ${ }^{39}$ we always assumed a constant ionic strength correction, so the derived equilibrium constants are conditional ones. This allows solving the set of mathematical equations into an analytical expression linking $D_{\mathrm{U}}$, the parameters of the model (see Section 3) and the initial chemical conditions (total amount of ligand, initial acidic concentration etc.). For all the models discussed in this work, this mathematical treatment is rather easy because the concentrations of $\mathrm{HNO}_{3}, \mathrm{H}^{+}, \mathrm{NO}_{3}{ }^{-}$and ligand (protonated or not, see Section 3.2) are always in large excess as compared to the metallic concentration.

Fitting procedures of ion concentrations and $D_{\mathrm{U}}$ values have been performed using dedicated Fortran sub-routines, inserted in the MINUIT minimization procedure (Simplex and Migrad procedures, least square adjustment of $\chi^{2}$ ) available through the CERN libraries, based on the mathematical expressions derived ( $D_{\mathrm{U}}$ values) or empirically chosen (ion concentrations). Because of the different experimental uncertainties arising from the measurement protocol for $D_{\mathrm{U}}$ and ion concentrations, minimizations have been performed on the basis of two different definitions of the $\chi^{2}$ criterion: 


$$
\begin{aligned}
& \chi^{2}=\left[\sum\left(M_{\text {cal }}-M_{\text {exp }}\right)^{2}\right]^{1 / 2} / N(\text { for ion concentration) } \\
& \chi^{2}=\left[\sum\left(\left(M_{\text {cal }}-M_{\text {exp }}\right) / M_{\text {cal }}\right)^{2}\right]^{1 / 2} / N\left(\text { for } D_{\mathrm{U}} \text { values }\right)
\end{aligned}
$$

where $M_{\text {cal }}$ and $M_{\exp }$ are the theoretical and experimental measure, respectively, and $N$ is the number of data points.

\section{Experimental results}

\subsection{Spectroscopic analysis of uranium(vI) extracted IL solutions}

We have shown previously that the distribution coefficients of uranium(vI) as a function of $\mathrm{HNO}_{3}$ concentration has a "boomerang shape", with a minimum of extraction at $\left[\mathrm{HNO}_{3}\right]$ $=2 \mathrm{M}$ (see Fig. 1). ${ }^{34}$ We have investigated the composition of two IL extracted solutions, chosen from this uranium extraction curve. The first one (sample A) was obtained from an aqueous solution with $\left[\mathrm{HNO}_{3}\right]=0.6 \mathrm{M}$. It corresponds to the first part of the extraction curve, where $D_{\mathrm{U}}$ decreases with $\left[\mathrm{HNO}_{3}\right]$. The second sample (sample B) was obtained by extraction from a 6.3 $\mathrm{M} \mathrm{HNO}_{3}$ aqueous solution, it corresponds to the second part of the extraction curve where $D_{\mathrm{U}}$ smoothly increases with $\mathrm{HNO}_{3}$ concentration. In both cases, the $\left[\mathrm{C}_{4} \mathrm{mim}\right]\left[\mathrm{Tf}_{2} \mathrm{~N}\right]$ phase contains $50 \mathrm{mM}$ DMDBMA, as used to obtain the extraction data displayed in Fig. 1.

3.1.1. UV-vis spectroscopy. The UV-vis spectra of those two IL solutions are compared in Fig. 2 with the one obtained by the extraction of uranyl in 1,2-dichloroethane (DCE). The shape of the sample A and B spectra is different, confirming the extraction of two different uranyl species in the DMDBMA/IL phase as a function of the initial $\mathrm{HNO}_{3}$ concentration. Moreover, the shape of the sample A is completely different from the one obtained in DCE, which means that the extracted uranyl species are of different nature in IL and in the molecular solvent at low acid concentration. The shape of the sample B shows some similitudes with the one of $\mathrm{U}(\mathrm{vI})$ extracted with DMDBMA into

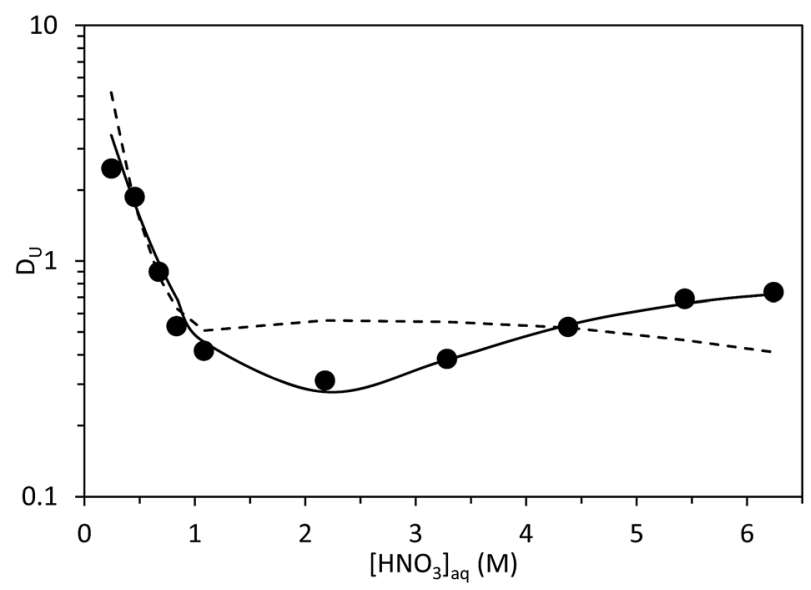

Fig. 1 Extraction data curve of uranium(vi) as a function of the nitric acid concentration ${ }^{34}$ (symbols), for [DMDBMA] $=50 \mathrm{mM}$. Lines represent data fits obtained by 2 models explained in part 4, taking into account the aqueous $\mathrm{Tf}_{2} \mathrm{~N}^{-}$concentrations values: model from ref. 34 (dotted line) and new model developed in this paper (solid line).

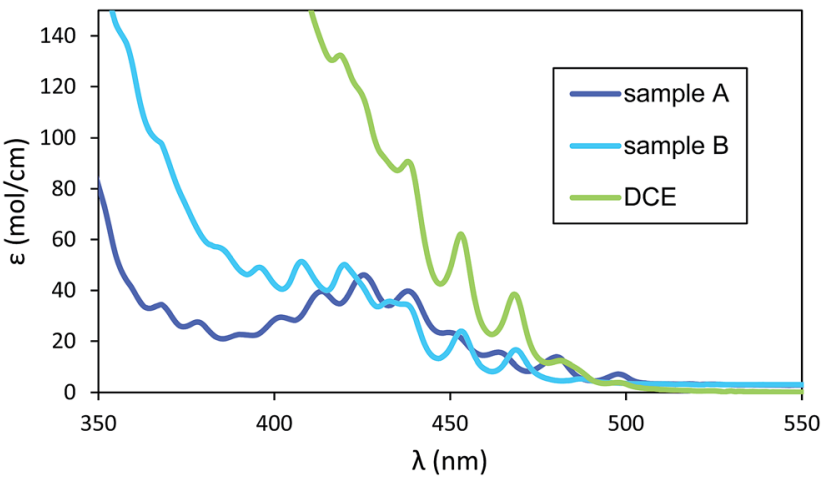

Fig. 2 UV-vis spectra of $U(\mathrm{VI})$ extracted species by 0.3 M DMDBMA into $\left[\mathrm{C}_{4}\right.$ mim] $\left[\mathrm{Tf}_{2} \mathrm{~N}\right]$ from 0.6 $\mathrm{M} \mathrm{HNO}_{3}(\mathrm{~A})$ and $6.3 \mathrm{M}(\mathrm{B})$, compared with the spectra of $U(\mathrm{VI})$ extracted in 1,2-dichloroethane from 3.3 $\mathrm{M} \mathrm{HNO}_{3}$.

DCE and benzene. ${ }^{32}$ This feature means that uranyl extracted species from $6.3 \mathrm{M} \mathrm{HNO}_{3}$ in IL are chemically close to those extracted in molecular solvents, $\mathrm{UO}_{2}\left(\mathrm{NO}_{3}\right)_{2}$. DMDBMA.

In order to get more information, we have compared the spectra of the extracted species with those of reference sample containing various ratios of nitrates and DMDBMA (see Fig. 3). In the absence of nitrate ions, the uranium/DMDBMA spectra display three main peaks at 412,425 and $438 \mathrm{~nm}$. The sample A spectrum exhibits the same shape with peaks at the same position. Thus we can suppose that the composition of the uranyl extracted complex at low acidity is of the same nature, formed only with DMDBMA molecules. The spectrum of sample B looks like those of reference samples containing nitrates and DMDBMA. On the latter, the 3 peaks displayed at 438,455 and $471 \mathrm{~nm}$ are typical of $\left[\mathrm{UO}_{2}\left(\mathrm{NO}_{3}\right)_{x}\right]$ units, ${ }^{40,41}$ they indicate the presence of nitrate ions in the uranium first coordination sphere and their intensity is proportional to the number of nitrate groups. We thus can assume that the complex extracted at high acidity contains some nitrate groups. At this stage, it is not possible to derive more information on the nature of the extracted species, and we have performed EXAFS experiments for that purpose.

3.1.2. EXAFS spectroscopy. Fig. 4 displays the EXAFS spectra and the corresponding Fourier transforms of uranyl samples described in Table 1. Fit results are given in Table S1.†

Sample A and B spectra are compared to reference solutions. In the reference samples $S 1 \_0 \_X$, we evidence the total complexation of DMDBMA molecules to uranyl in the ionic liquid for solutions containing 1 or 2 equivalents of ligands. For the S1_0_3 sample containing 3 equivalents of DMDBMA, an average ratio of $4.5 \mathrm{C}$ is found. According to the uncertainties on this value, it would correspond to the complexation of 2 or 3 DMDBMA in the uranyl coordination sphere. We can also envision the simultaneous presence of the $1: 2$ and $1: 3$ complexes in solution. The $1: 3$ stoichiometry is reached for the S1_0_4 sample which contains a 4 fold amount of ligand compared to uranyl. For all stoichiometries, the ligand is complexed to uranyl by a bidentate coordination, as already noticed in the solid state. ${ }^{27,42}$ Nitrate ions are also strong complexants to uranium(vI). When a sum of 3 ligands (nitrates + 

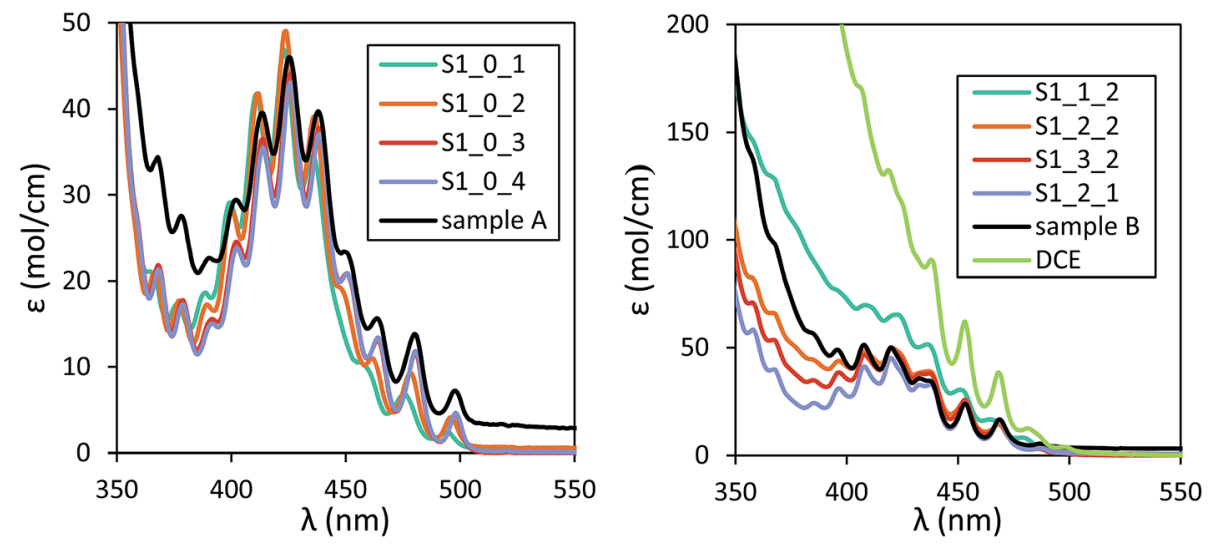

Fig. 3 UV-vis spectra comparison between extracted IL samples and reference solutions (see nomenclature of samples in Table 1).

DMDBMA) per uranyl is added in solution, only one species is formed corresponding to the filling of the uranyl equatorial plane by the 3 ligands: $\mathrm{UO}_{2}\left(\mathrm{NO}_{3}\right)(\mathrm{DMDBMA})_{2}$ in sample $\mathrm{S} 1 \_1 \_2$ and $\mathrm{UO}_{2}\left(\mathrm{NO}_{3}\right)_{2}(\mathrm{DMDBMA})$ in sample $\mathrm{S} 1 \_2 \_1$. When the total number of ligands per uranyl is above 3 , then a mixture of complexes is formed in solution, as a sign of the competitive complexation of nitrates ions and DMDBMA ligands. As a consequence, EXAFS fit results show the formation of a mixture of $\mathrm{UO}_{2}\left(\mathrm{NO}_{3}\right)_{2}(\mathrm{DMDBMA})$ and $\mathrm{UO}_{2}\left(\mathrm{NO}_{3}\right)(\mathrm{DMDBMA})_{2}$ in both S1_2_2 and S1_3_2 samples.

Let us turn now to the extracted samples. In dichloroethane, our results are in agreement with literature data as we evidence the extraction of the neutral $\mathrm{UO}_{2}\left(\mathrm{NO}_{3}\right)_{2}$ (DMDBMA). In the ionic liquid, the extracted species are of different nature according to the initial acidic concentration in the aqueous phase. At low $\left[\mathrm{HNO}_{3}\right]$, the uranyl species are cationic complexes composed
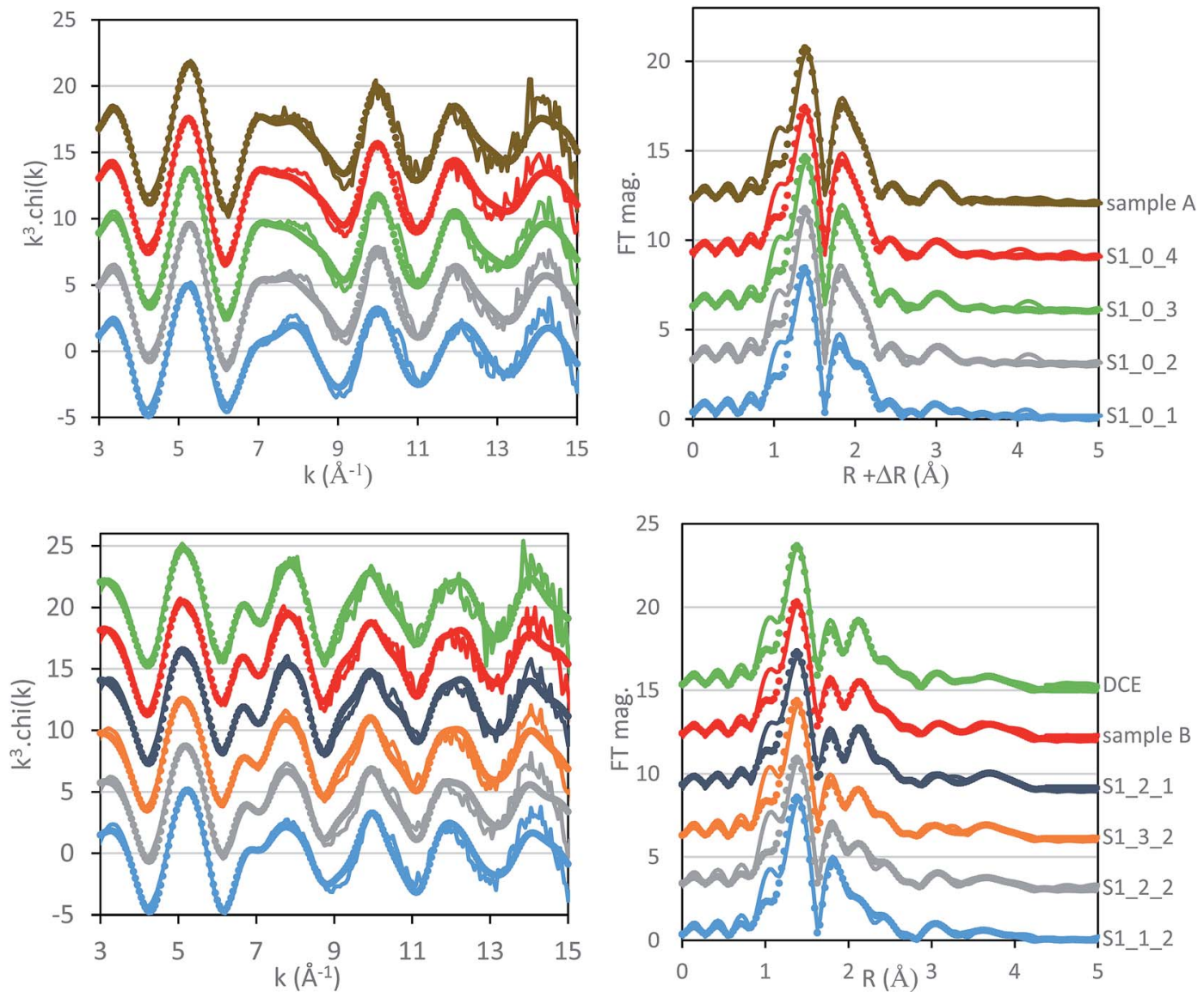

Fig. 4 EXAFS (left) and Fourier transform (right) of uranyl samples, spectra are shifted along the $y$-axis for sake of clarity. Comparison between extracted samples and reference ones. See Table 1 for samples composition. 
only by DMDBMA ligands. As for the reference sample S1_0_3, the average number of ligand coordinated to uranyl stands between 2 and 3 . It can be interpreted by the presence of 2 different complexes in solution ( $\mathrm{UO}_{2}(\mathrm{DMDBMA})_{2}{ }^{2+}$ and $\mathrm{UO}_{2}(-$ DMDBMA $)_{3}{ }^{2+}$ ). However, according to the large uncertainty on the coordination number determination, we can also envision the presence of an unique species, either $\mathrm{UO}_{2}(\mathrm{DMDBMA})_{2}{ }^{2+}$ or $\mathrm{UO}_{2}(\mathrm{DMDBMA})_{3}{ }^{2+}$. Therefore, in the following, the cationic extracted species will be written as $\mathrm{UO}_{2}(\mathrm{DMDBMA})_{x}{ }^{2+}$ species with $2 \leq x \leq 3$. At high $\left[\mathrm{HNO}_{3}\right]$, uranyl is extracted in the IL phase as the neutral $\mathrm{UO}_{2}\left(\mathrm{NO}_{3}\right)_{2}$ (DMDBMA).

\subsection{Effect of DMDBMA concentration on the IL ions solubility in the aqueous phase and on the acid extraction in the IL phase}

All NMR measurements in this study were carried out with samples containing deuterium oxide, $\mathrm{D}_{2} \mathrm{O}$ and deutero-nitric acid, $\mathrm{DNO}_{3}$. Nitric acid and water with hydrogen atoms substituted by hydrogen isotope, deuterium, exhibit nearly identical chemical behavior. Thus, in order to simplify the notation we use only the name nitric acid, $\mathrm{HNO}_{3}$, in the following. In Fig. 5 we compare the solubility of IL ions in aqueous phases as a function of $\mathrm{HNO}_{3}$ concentration after contacting nitric acid solutions with neat $\left[\mathrm{C}_{4} \mathrm{mim}\right]\left[\mathrm{Tf}_{2} \mathrm{~N}\right]^{15}$ or with an organic phase composed of $50 \mathrm{mM}$ DMDBMA in $\left[\mathrm{C}_{4} \mathrm{mim}\right]\left[\mathrm{Tf}_{2} \mathrm{~N}\right] .^{43}$

The variation of the initial nitric acid concentration results in a noticeable change of the ILs' ion individual solubilities for both biphasic systems, with and without DMDBMA in the IL phase. Without DMDBMA, the solubility of $\mathrm{C}_{4} \mathrm{mim}^{+}$increases monotonously with the increase in the acid concentration, to reach a value of $0.1 \mathrm{M}$ for $\left[\mathrm{HNO}_{3}\right]=6 \mathrm{M}$. The introduction of 50 mM DMDBMA in the IL phase leads to a slight increase of the $\mathrm{C}_{4} \mathrm{mim}^{+}$solubility as compared to neat IL. Above $3 \mathrm{M}$ of $\mathrm{HNO}_{3}$ there is no substantial difference between the IL cation solubilities for the biphasic systems with and without DMDBMA in the organic phase.
The opposite trend is observed for the $\mathrm{Tf}_{2} \mathrm{~N}^{-}$solubility in $\mathrm{HNO}_{3}$ aqueous phases. Indeed, it appears that DMDBMA significantly reduces the amount of $\mathrm{Tf}_{2} \mathrm{~N}^{-}$anions in the aqueous phase, whatever the initial nitric acid concentration. Fig. 6 displays the solubility of IL ions in the aqueous phase as a function of the DMDBMA concentration for two nitric acid concentrations: $0.45 \mathrm{M}$ and $4.51 \mathrm{M}$. Two different trends are observed for each ion. The IL cation solubility in the aqueous phase increases with the DMDBMA concentration, while the IL anion concentration decreases. As a conclusion, we show that the solubility of each IL ion in the aqueous phase is different as a function of the nitric acid and ligand concentration, so that it is not possible to consider that $\left[\mathrm{C}_{4} \mathrm{mim}^{+}\right]_{\mathrm{aq}, \mathrm{eq}}$ and $\left[\mathrm{Tf}_{2} \mathrm{~N}^{-}\right]_{\mathrm{aq}, \mathrm{eq}}$ are equal and constant.

By contacting an acidic aqueous phase and an IL phase, even without an extractant and without a metallic ion, part of the acid is extracted in the IL phase. This has been observed previously ${ }^{\mathbf{1 4}}$ and in the case of $\left[\mathrm{C}_{4} \mathrm{mim}\right]\left[\mathrm{Tf}_{2} \mathrm{~N}\right]$ and $\mathrm{HNO}_{3}$, the transfer of $\mathrm{H}^{+}$from the aqueous to the IL phase amounts to $6 \%$ of the initial acid concentration. Addition of an extractant further increases this $\mathrm{H}^{+}$transfer, as observed previously for the same $\mathrm{H}_{2} \mathrm{O} / \mathrm{HNO}_{3} / / \mathrm{DMDBMA} /\left[\mathrm{C}_{4} \mathrm{mim}\right]\left[\mathrm{Tf}_{2} \mathrm{~N}\right]$ mixtures $^{34}$ and confirmed by our additional experiments, as evidenced in Fig. 7, which shows the evolution of the $\mathrm{H}^{+}$ion at equilibrium in the aqueous $\mathrm{HNO}_{3}$ phase as a function of the ligand concentration in $\left[\mathrm{C}_{4} \mathrm{mim}\right]\left[\mathrm{Tf}_{2} \mathrm{~N}\right]$. The "natural" $\mathrm{H}^{+}$transfer, equal to $6 \%$ is indicated as a horizontal dotted line, evidencing the increase in $\mathrm{H}^{+}$transfer due to the DMDBMA addition.

We previously ascribed these variations to the protonation of the DMDBMA moiety according to:

$$
\mathrm{DMDBMA}_{\text {org }}+\mathrm{H}_{\text {org }}{ }^{+} \Leftrightarrow \mathrm{DMDBMAH}_{\text {org }}{ }^{+}
$$

and we could recover our previous data with a protonation constant in the IL phase equal to $K_{\mathrm{L}}=90 .{ }^{34}$ Our new data, as depicted in Fig. 7, agree well with the two values of $K_{\mathrm{L}}=90$ and $6 \%$ of "natural" $\mathrm{H}^{+}$transfer. Fixing the ligand protonation
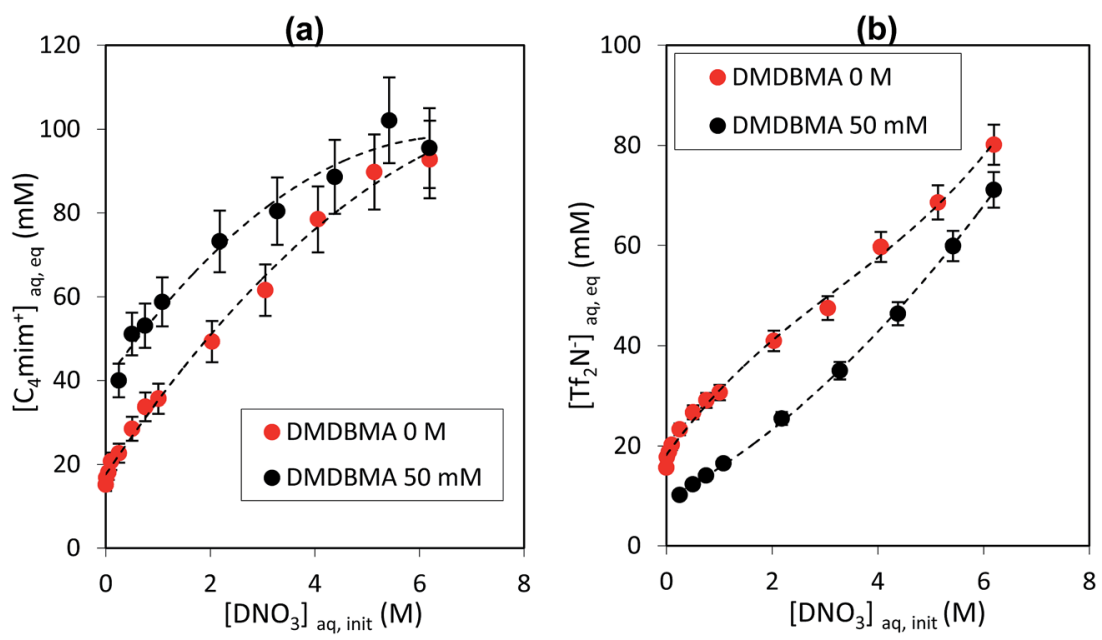

Fig. 5 Comparison of the $\mathrm{C}_{4} \mathrm{mim}^{+}$(a) and $\mathrm{Tf}_{2} \mathrm{~N}^{-}$(b) aqueous concentrations at equilibrium as a function of the initial nitric acid concentration in the aqueous phase without DMDBMA (red symbols, from ref. 15) and with DMDBMA 50 mM (black symbols, from ref. 43). Dotted lines represent the data fits used for the modeling (see Section 4). 

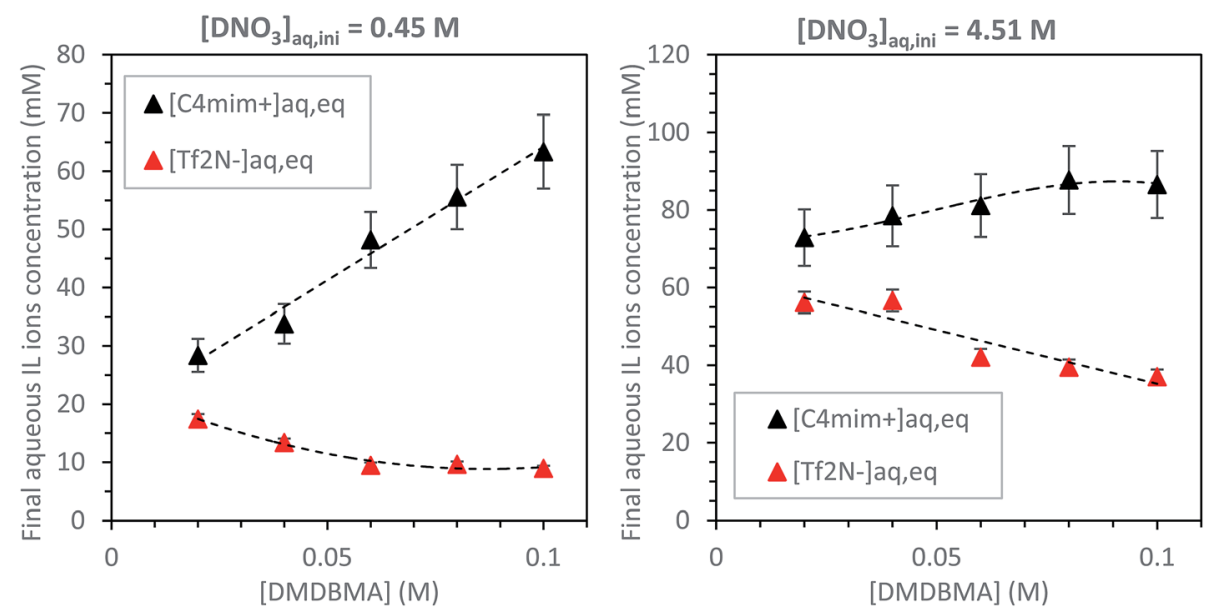

Fig. 6 Aqueous concentration at equilibrium of $\mathrm{C}_{4} \mathrm{mim}^{+}$and $\mathrm{Tf}_{2} \mathrm{~N}^{-}$as a function of the DMDBMA concentration in $\left[\mathrm{C}_{4}\right.$ mim] $\left[\mathrm{Tf}_{2} \mathrm{~N}\right]$, at two nitric acid concentrations: $0.45 \mathrm{M}$ (left) and 4.51 M (right). Dotted lines represent the data fits used for the modeling (see Section 4).
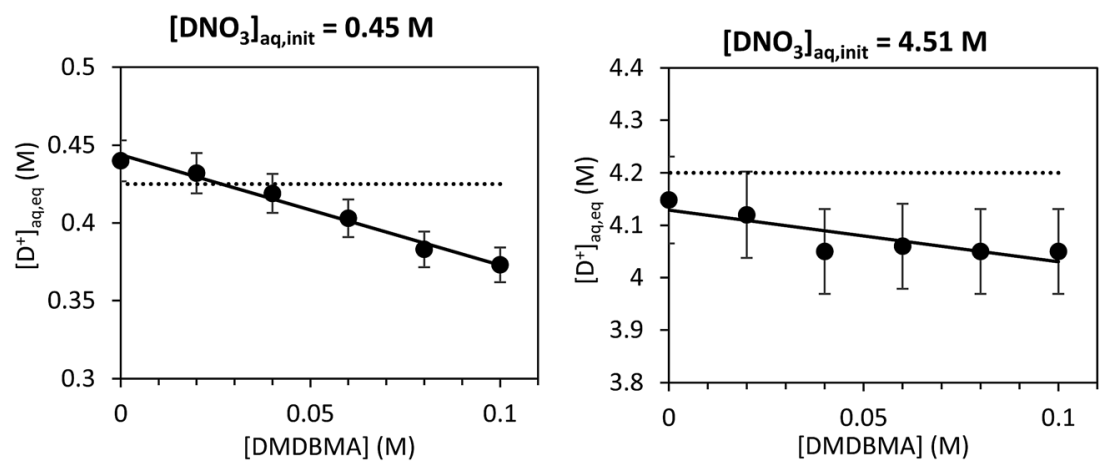

Fig. 7 Evolution of the final concentration of $\mathrm{D}^{+}$ion in the aqueous $\mathrm{DNO}_{3}$ phase as a function of the ligand concentration in the ionic liquid. $\left[\mathrm{DNO}_{3}\right]_{\mathrm{aq} \text {,init }}=0.45 \mathrm{M}$ and $4.51 \mathrm{M}$ (error bars $=2 \%$ ). Dotted lines represent the acid uptake without ligand. Solid lines represent the data fits used for the modeling (see Section 4).

constant at $K_{\mathrm{L}}=90$ leads to concentration of free DMDBMA in the IL always at least 40 times above the initial metal concentration. Thus this quantity has been considered as a constant for the calculations to follow.

\section{Extraction mechanism}

In a first step, we consider our previous model, as detailed in: ${ }^{34}$

$$
\begin{aligned}
& \mathrm{UO}_{2}{ }^{2+}{ }_{\mathrm{aq}}+2 \mathrm{DMDBMA}_{\mathrm{org}}+2 \mathrm{H}_{\mathrm{org}}{ }^{+} \Leftrightarrow
\end{aligned}
$$

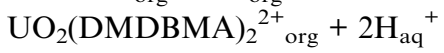

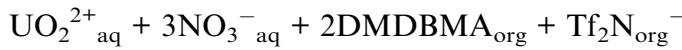

$$
\begin{aligned}
& \Leftrightarrow \mathrm{UO}_{2}\left(\mathrm{NO}_{3}\right)_{3}(\mathrm{DMDBMA})_{2}{ }^{-} \text {org }{ }^{-} \mathrm{Tf}_{2} \mathrm{~N}_{\mathrm{aq}}{ }^{-}
\end{aligned}
$$

Eqn (4) and (5) are accompanied by eqn (3) for ligand protonation, and also by the two successive nitrate-uranyl complexations in the aqueous phase. By contrast to our previous study, in which we erroneously assumed the IL's cation and anion solubilities in water to be constant, we now should take into account the $\left[\mathrm{Tf}_{2} \mathrm{~N}^{-}\right]$variations as a function of the initial concentrations of $\mathrm{HNO}_{3}$ (fixed DMDBMA at $50 \mathrm{mM}$ ) and
DMDBMA (fixed $\mathrm{HNO}_{3}$ at $0.49 \mathrm{M}$ and $4.4 \mathrm{M}$ ) as illustrated in Fig. 5 and 6. These quantities intervene in the mass action law and in the charge balance (see Section 2.4). This has been done by use of empirical polynoms according to:

For $[\mathrm{DMDBMA}]_{\text {init }}=50 \mathrm{mM}$ and $\left[\mathrm{HNO}_{3}\right]_{\text {init }}$ from $0.25 \mathrm{M}$ to $6.19 \mathrm{M}$ :

$$
\begin{gathered}
{\left[\mathrm{Tf}_{2} \mathrm{~N}^{-}\right]=0.7046\left[\mathrm{HNO}_{3}\right]_{\text {init }}{ }^{2}+5.538\left[\mathrm{HNO}_{3}\right]_{\text {init }}+9.37} \\
{\left[\mathrm{C}_{4} \mathrm{mim}^{+}\right]=-1.3189\left[\mathrm{HNO}_{3}\right]^{2}+17.556\left[\mathrm{HNO}_{3}\right]+39.85} \\
\text { For }\left[\mathrm{HNO}_{3}\right]=0.445 \mathrm{M} \text { and }[\mathrm{DMDBMA}]_{\text {init }} \\
\text { from } 0.02 \mathrm{M} \text { to } 0.1 \mathrm{M}:
\end{gathered}
$$

$\left[\mathrm{Tf}_{2} \mathrm{~N}^{-}\right]=1923.2[\mathrm{DMDBMA}]^{2}-334.54[\mathrm{DMDBMA}]+23.384$

$$
\left[\mathrm{C}_{4} \mathrm{mim}^{+}\right]=458.7[\mathrm{DMDBMA}]+18.336
$$

For $\left[\mathrm{HNO}_{3}\right]_{\text {init }}=4.4 \mathrm{M}$ and $[\mathrm{DMDBMA}]$ from $0.02 \mathrm{M}$ to $0.1 \mathrm{M}$ :

$$
\left[\mathrm{Tf}_{2} \mathrm{~N}^{-}\right]=-242.3[\mathrm{DMDBMA}]+59.455
$$




\section{$\left[\mathrm{C}_{4} \mathrm{mim}^{+}\right]=5.03 \times 10^{4}[\mathrm{DMDBMA}]^{3}+7333[\mathrm{DMDBMA}]^{2}-$ 85.21[DMDBMA $]+72.3$}

In all equations above, $\left[\mathrm{C}_{4} \mathrm{mim}^{+}\right]$and $\left[\mathrm{Tf}_{2} \mathrm{~N}^{-}\right]$are in $\mathrm{mM}$, [DMDBMA $]$ and $\left[\mathrm{HNO}_{3}\right]$ are in $\mathrm{M}$.

The numerical coefficients of these polynoms have been determined through a fitting procedure (see Section 2.4) and Fig. 5 and 6 illustrate the quality of fitting polynoms. Considering the values obtained and the empirical status of the expressions, care has been taken to never extrapolate $\mathrm{C}_{4} \mathrm{mim}^{+}$ and $\mathrm{Tf}_{2} \mathrm{~N}^{-}$concentration values outside the ranges of applicability given above. This range is slightly narrower than that used in our previous publication, owing to a limited availability of the DMDBMA compound.

Another important phenomenon to be taken into account and that was not considered in our previous study is the wellknown nitric acid association above $3 \mathbf{M}^{15,44}$ that impacts the concentration values of the free nitrate ions in the aqueous phase (appearing in eqn (5) and also in the successive nitrate/ uranyl complexations). We took advantage of the data by Ruas and collaborators ${ }^{44}$ who derived the free and associated nitrate proportions in aqueous solutions of nitric acid, up to $13.6 \mathrm{M}$. We adjusted the experimental data by use of a polynom as:

$$
\begin{gathered}
{\left[\mathrm{HNO}_{3}\right]<3 \mathrm{M}: \text { no } \mathrm{HNO}_{3} \text { association, }} \\
\text { i.e. }\left[\mathrm{NO}_{3}{ }^{-}\right]_{\mathrm{aq}, \text { init }}=\left[\mathrm{HNO}_{3}\right]_{\mathrm{aq}, \text { init }} \\
{\left[\mathrm{HNO}_{3}\right]>3 \mathrm{M}:\left[\mathrm{NO}_{3}{ }^{-}\right]_{\mathrm{aq}, \text { init }}=-0.0703 \times\left[\mathrm{HNO}_{3}\right]_{\mathrm{aq}, \text { init }}{ }^{2}} \\
+1.2438 \times\left[\mathrm{HNO}_{3}\right]_{\mathrm{aq}, \text { init }}-0.3106
\end{gathered}
$$

The excellent agreement between the experimental data of Ruas and collaborators and the fitted polynom is illustrated in Fig. S1. $\dagger$ The polynom was thus safely used in our limited range $0-6 \mathrm{M}$.

Although this is an improvement in the completeness of the model, it is still not perfect because the effect of all other ions $\left(\mathrm{C}_{4} \mathrm{mim}^{+}, \mathrm{Tf}_{2} \mathrm{~N}^{-}, \mathrm{UO}_{2}{ }^{2+}\right.$ etc. $)$ is not described. We only rely on the fact that as these additional concentrations are low, the global effect should be small.

Under these assumptions, we attempted a fit of the three series of extraction data all together: (i) $D_{\mathrm{U}} v s$. $\left[\mathrm{HNO}_{3}\right]_{\text {init }}$ at $[$ DMDBMA $]=50 \mathrm{mM}$ (ii) $D_{\mathrm{U}} v s$. $[\mathrm{DMDBMA}]$ at $\left[\mathrm{HNO}_{3}\right]=0.5 \mathrm{M}$ and (iii) $D_{\mathrm{U}} v s$. [DMDBMA $]$ at $\left[\mathrm{HNO}_{3}\right]=4.4 \mathrm{M}$.

Both $D_{\mathrm{U}} v s$. [DMDBMA] variations are nicely fitted (see Fig. S2 $\dagger$ ), and the $D_{\mathrm{U}} v s$. $\left[\mathrm{HNO}_{3}\right]$ fit is satisfactory too below $1 \mathrm{M}$ $\mathrm{HNO}_{3}$, but the fit significantly deviates from the experimental data above $1 \mathrm{M} \mathrm{HNO}_{3}$ as shown in Fig. 1 (dotted line). The discrepancy evidenced in Fig. 1 is mainly due to the $\mathrm{Tf}_{2} \mathrm{~N}^{-}$ variations, suffering an increase of $c a$. a factor of 4.6 in the range 1-6 $\mathrm{M}$ of $\mathrm{HNO}_{3}$ (see Fig. 5b). This obviously strongly impacts the $D_{\mathrm{U}}$ values at high acidic initial concentrations, for which the postulated anionic exchange is dominating the extraction mechanism. The previous model thus appears inappropriate.
Therefore, in a second step, we propose a refined extraction mechanism, in qualitative agreement with the new EXAFS and UV-vis experimental evidences detailed above:

At low acid concentration:

$$
\begin{aligned}
\mathrm{UO}_{2}{ }^{2+}{ }_{\mathrm{aq}} & +(2-t) \mathrm{H}_{\mathrm{org}}{ }^{+}+t \mathrm{C}_{4} \operatorname{mim}_{\mathrm{org}}{ }^{+}+x \mathrm{DMDBMA}_{\mathrm{org}}{ }^{2+} \\
& +z_{1} \mathrm{HNO}_{3} \Leftrightarrow\left[\mathrm{UO}_{2}\left(\mathrm{DMDBMA}_{x}\left(\mathrm{HNO}_{3}\right)_{z_{1}}\right]_{\text {org }}{ }^{2+}\right. \\
& +(2-t) \mathrm{H}_{\mathrm{aq}}{ }^{+}+t \mathrm{C}_{4} \mathrm{mim}_{\mathrm{aq}}{ }^{+}
\end{aligned}
$$

At high acid concentration:

$$
\begin{aligned}
\mathrm{UO}_{2}{ }^{2+}{ }_{\mathrm{aq}}+y \mathrm{DMDBMA}_{\mathrm{org}}+2 \mathrm{NO}_{3}{ }^{-}{ }_{\mathrm{aq}}+z_{2} \mathrm{HNO}_{3 \mathrm{aq}} \\
\Leftrightarrow \mathrm{UO}_{2}\left(\mathrm{NO}_{3}\right)_{2}(\mathrm{DMDBMA})_{y}\left(\mathrm{HNO}_{3}\right)_{z_{2} \mathrm{org}}
\end{aligned}
$$

where $x, y$ and $z_{1}, z_{2}$ are accounting for possible different stoichiometric coefficients of the ligand or $\mathrm{HNO}_{3}$ respectively, at low and high acidity. $K_{+0}$ is the extraction equilibrium constant of the cationic exchange, occurring with $(2-t) \mathrm{H}^{+}$and $t \mathrm{C}_{4} \mathrm{mim}^{+}$ cations from the IL phase, at low acid concentration. $K_{\mathrm{n}}$ is the equilibrium constant for the ion pair mechanism occurring at high acid concentration. We also include eqn (3), describing the DMDBMA protonation and the complexation between uranyl and nitrates. Eqn (6) is in agreement with the EXAFS data, ruling out nitrate ions within the first coordination sphere of the extracted species at low acidities. Conversely, eqn (7) involves a neutral species due to the concomitant extraction of $\mathrm{UO}_{2}{ }^{2+}$ and two nitrate ions and this neutral species also possibly contains some $\mathrm{HNO}_{3}$ neutral entities in the second coordination sphere $\left(z_{2}\right)$.

Eqn (6) and (7) are balanced chemical equations and the question is raised about the source of $\mathrm{HNO}_{3}$ entities which possibly appear in the extracted species as this is again linked to the nitric association above $3 \mathrm{M}$. Therefore, the two possible routes for associating $\mathrm{HNO}_{3}$ to the extracted metallic species above $3 \mathrm{M}$ (either from remaining $\mathrm{H}^{+}$and $\mathrm{NO}_{3}{ }^{-}$or from newly formed $\mathrm{HNO}_{3}$ ) lead to differences in the way to express the mass action law. Of course, it is possible that the formation of the complex is a mixed scenario between these two but we consider only the two limiting possibilities.

All these assumptions allow solving the set of mathematical equations into an analytical expression linking $D_{\mathrm{U}}$, the parameters of the model $\left(K_{\mathrm{L}}, K_{+0}, K_{\mathrm{n}}, t, x, y\right.$ and $\left.z_{1}, z_{2}\right)$ and the initial chemical conditions (total amount of ligand, initial acidic concentration etc.). The two analytical expressions of $D_{\mathrm{U}}$, differing according to the source of $\mathrm{HNO}_{3}$ in the complex, were thus fitted to the experimental $D_{\mathrm{U}}$ values already collected $\left(D_{\mathrm{U}}\right.$ vs. $\mathrm{HNO}_{3}$ at fixed DMDBMA concentration - see Fig. 1 - and $D_{\mathrm{U}}$ vs. DMDBMA concentration at two fixed $\mathrm{HNO}_{3}$ concentrations, i.e. $\left[\mathrm{HNO}_{3}\right]=0.49 \mathrm{M}$ and $\left[\mathrm{HNO}_{3}\right]=4.40 \mathrm{M}-$ see Fig. $\left.\mathrm{S} 2 \dagger\right)$.

Several trials were performed that all concluded that the source of $\mathrm{HNO}_{3}$ within the extracted species is by aggregation of $\mathrm{H}^{+}$and $\mathrm{NO}_{3}{ }^{-}$, even above $3 \mathrm{M}$ of initial nitric acid. This is in line with the fact that these two ions are the major components of concentrated nitric acid solutions even if associated $\mathrm{HNO}_{3}$ exists (see Fig. $\mathrm{S} 1 \dagger$ ). As for the value of $t$, it has to be nil to comply with the absence of effect of $\mathrm{C}_{4} \mathrm{mim}^{+}$addition. ${ }^{34}$ It was therefore set to zero in all subsequent trials discussed below. 
We then examined the impact of allowing $x, y$ and $z$ to be either positive integers only, as is chemically reasonable, or to be floating real positive values, as is mathematically conceivable. As expected, the $\chi^{2}$ value for floating values is slightly better than for imposed integer values, but the floating values are all rather close to integers except for $x$. This last result is in agreement with the EXAFS data, which also led to an intermediate value of $x$, ranging between 2 and 3 .

As an illustration, fitted values are collected in Table 2 for floating parameters and integer parameters.

Consequently, we plotted the best fit obtained for floating parameters in Fig. 1 (and S2†) while we summarize the best chemical model using integer values as:

At low acid concentration the chosen integer $x$ value corresponds to the lowest $\chi^{2}$ (see Table 2 ):

$$
\begin{aligned}
\mathrm{UO}_{2}{ }^{2+} \text { aq } & +2 \mathrm{H}_{\mathrm{org}}{ }^{+}+ \\
& 2 \mathrm{DMDBMA}_{\mathrm{org}} \Leftrightarrow \\
& \mathrm{UO}_{2}\left(\mathrm{DMDBMA}_{2}{ }^{2+}{ }_{\mathrm{org}}+2 \mathrm{H}_{\mathrm{aq}}{ }^{+}\right.
\end{aligned}
$$

At high acid concentration:

$$
\begin{array}{r}
\mathrm{UO}_{2}{ }^{2+}{ }_{\mathrm{aq}}+\mathrm{DMDBMA}_{\mathrm{org}}+2 \mathrm{NO}_{3}{ }^{-}{ }_{\mathrm{aq}}+\mathrm{HNO}_{3 \mathrm{aq}} \Leftrightarrow \\
\mathrm{UO}_{2}\left(\mathrm{NO}_{3}\right)_{2}(\mathrm{DMDBMA})\left(\mathrm{HNO}_{3}\right)_{\mathrm{org}}
\end{array}
$$

As is seen in Fig. 1, this new model is able to recover the experimental variations in a very satisfactory way and, as compared to our previous proposal, the improvement is obvious above $1 \mathrm{M} \mathrm{HNO}_{3}$. Our trials also clearly show that one $\mathrm{HNO}_{3}$ entity co-extracted with the ion pair is mandatory to obtain a reasonable fit. Actually, in the absence of $\mathrm{HNO}_{3}$ entity for the extraction mechanism at high acidity, the $\chi^{2}$ values is doubled as compared to the value at $\chi^{2}=0.107$ (floating option).

This new model obtained from a much complete data set gives different results than our previous one at high acidic concentration, when we suggested the extraction of the $\left[\mathrm{UO}_{2}(-\right.$ $\left.\left.\mathrm{NO}_{3}\right)_{3} \mathrm{DMDBMA}\right]^{-}$moieties. This assumption is discarded by our new EXAFS and UV-vis experiments, and the new analytical model developed is based on the extraction of the neutral $\mathrm{UO}_{2}\left(\mathrm{NO}_{3}\right)_{2}(\mathrm{DMDBMA})\left(\mathrm{HNO}_{3}\right)$. The discrepancy between these two complexes is only apparent as in both cases, the extraction of uranyl implies 3 nitrate entities. But this involves significant chemical differences, as one of the nitrate group lies in the uranyl second coordination sphere as $\mathrm{HNO}_{3}$. This hypothesis is in agreement with the EXAFS results. Indeed, the presence of this undissociated $\mathrm{HNO}_{3}$ cannot be evidenced by this technique which is able to look only at a short distance around the absorbing atom (here U). Actually the extraction of complexes

Table 2 Fitted values obtained by the modeling of extraction curve data

\begin{tabular}{lrrlllll}
\hline & $K_{+0}$ & $K_{\mathrm{n}}$ & $x$ & $y$ & $z_{1}$ & $z_{2}$ & $\chi^{2}$ \\
\hline Floating & $3.0 \times 10^{7}$ & 16.0 & 2.34 & 1.01 & 0.38 & 1.0 & 0.107 \\
Integer & $6.9 \times 10^{8}$ & 17.8 & $3^{a}$ & 0.99 & 0.67 & 0.9 & 0.181 \\
Integer & $4.4 \times 10^{5}$ & 1.4 & $2^{a}$ & 0.97 & 0.0 & 1.1 & 0.169 \\
\multicolumn{2}{l}{ Fixed value. } & & & & & &
\end{tabular}

$\mathrm{UO}_{2}\left(\mathrm{NO}_{3}\right)_{2} \mathrm{~L} \cdot \mathrm{HNO}_{3}(\mathrm{~L}=$ DMDBMA or DMDOMA $)$ was previously stated by Musikas et al. ${ }^{\mathbf{3 0 , 3 1}}$ for molecular solvents, on the basis of the strong affinity of malonamide molecules with nitric acid. Our study tends to prove that the same kind of species is able to form in ionic liquids.

In the uranyl/DMDBMA extraction system, adding $\mathrm{Tf}_{2} \mathrm{~N}^{-}$ ions at high nitric concentration in the aqueous phase diminishes the extraction efficiency of uranium (see Fig. 9 of ref. 34, up to $1 \mathrm{M} \mathrm{LiTf}_{2} \mathrm{~N}$ added). It is often attractive to conclude on this sole $D_{\mathrm{U}}=f\left([\mathrm{IL} \text { ions }]_{\mathrm{aq}}\right)$ curves that IL ions play a direct role on the extraction mechanism, but our present results show that the phenomenon evidenced may only be a side-effect of the introduction of IL ions in the aqueous phase. In the present case, $\mathrm{Tf}_{2} \mathrm{~N}$ anions do not play an active role in the extraction mechanism, thus questions arise on their effect on the aqueous phase speciation. $\mathrm{HTf}_{2} \mathrm{~N}$ is a strong acid, ${ }^{45,46}$ and we may envision a change in the $\mathrm{HNO}_{3}$ speciation at high concentration in presence of $\mathrm{Tf}_{2} \mathrm{~N}^{-}$, with a decrease of the amount of associated $\mathrm{HNO}_{3}$. The aqueous phase speciation may also be disturbed by the change in the solution ionic strength. Therefore, the relevance of the experiment itself (adding artificially an IL ion to the aqueous phase in order to demonstrate a metallic ion extraction mechanism) may be questioned. We show here that the result is not the consequence of a uranium extraction mechanism but probably the consequence of a change in the initial aqueous speciation. In fact, it appears difficult (if not impossible) to distinguish between an anion exchange effectively implying $\mathrm{Tf}_{2} \mathrm{~N}^{-}$anions from an ion pairing mechanism which would be disturbed by the addition of a $\mathrm{Tf}_{2} \mathrm{~N}^{-}$salt. The same comment may be made for experiments consisting in introducing an IL cation salt in acidic aqueous phases in order to evidence a possible cation exchange mechanism.

As it is written in our new chemical model, the uranium(vi) extraction with DMDBMA in an ionic liquid is the sole consequence of its interactions with the ligand and nitric acid, the ionic liquid ions have no direct role on the extraction. As a matter of fact, the uranyl solvate extraction at low acidic concentration can be explained by the exchange with 2 protons while at high acid concentration we show the extraction of a neutral complex as in molecular solvents. However, it does not prevent a pollution of the aqueous phase with the IL ions which occurs independently of the uranium partitioning, as show in Fig. 5 and 6. So far, many efforts were made in order to avoid ion-exchange mechanism, arguing on the fact that the subsequent loss of IL ions is one of the major drawbacks for an industrial foreseen application. ${ }^{47-49}$ Actually, we show that the main point to be addressed is the mineral acid aqueous phase/ ionic liquid interactions. It is important to recall that the IL's ion solubilities, in the absence of $\mathrm{U}(\mathrm{vI})$, are never below $10 \mathrm{mM}$ and can reach $100 \mathrm{mM}$. These figures have to be compared to the metal ion concentrations used in laboratory extraction experiments, which lie usually between trace amounts (especially for actinides) to some $\mathrm{mM}$ ( $6 \mathrm{mM}$ in our present study). In this condition, the IL pollution of the aqueous phase from metal ions extraction is marginal comparing to the one occurring "naturally" by phase contact. The situation may be different in the frame of industrial applications where the aqueous phase 
metal concentration would be much higher. But it seems impossible to draw direct conclusions on the mechanism involved in this case from results obtained at much lower metal ion concentration. Indeed, the effect on the aqueous phase speciation and the subsequent solubility of IL in this phase need to be investigated.

\section{Conclusion}

We demonstrate that the extraction of uranium(vi) with a malonamide DMDBMA ligand into the hydrophobic $\left[\mathrm{C}_{4} \mathrm{mim}\right]$ $\left[\mathrm{Tf}_{2} \mathrm{~N}\right]$ ionic liquid is performed without the help of IL ions, over the whole $\mathrm{HNO}_{3}$ acidic range. By coupling spectroscopic analysis of the extracted species and a modelling of the extraction data, we show that $\left[\mathrm{UO}_{2}(\mathrm{DMDBMA})_{x}\right]^{2+}(2 \leq x \leq 3)$ species are extracted by an ion-exchange mechanism with 2 protons at $\left[\mathrm{HNO}_{3}\right]<1 \mathrm{M}$, while at high nitric acid concentration, a neutral solvate composed of ligand molecules and nitric acid is formed. However, it does not avoid a noticeable pollution of the aqueous phase with IL ions, just by contact of the two phases. At this stage, two paths emerge for a future use of IL for metal ion partitioning: (i) taking advantages of the large distribution coefficient while accepting the IL loss in the aqueous phase, or (ii) using extracting systems that diminish the aqueous phase pollution (using very hydrophobic IL, for instance), eventually in disfavor of the extraction efficiency.

\section{Acknowledgements}

The EXAFS work has been supported by the European FP7 TALISMAN project, under contract with the European Commission. We acknowledge the ROBL staff for their assistance during EXAFS measurements. The authors gratefully acknowledge the help of Dr Lionel Allouche, Dr Bruno Vincent and Maurice Coppe (Institute of Chemistry, University of Strasbourg, France) for the NMR measurements.

\section{References}

1 S. J. Yoon, J. G. Lee, H. Tajima, A. Yamasaki, F. Kiyono, T. Nakazato and H. Tao, J. Ind. Eng. Chem., 2010, 16, 350.

2 E. Quijada-Maldonado, J. Romero and I. Osorio, Hydrometallurgy, 2016, 159, 54.

3 S. Dai, Y. H. Ju and C. E. Barnes, J. Chem. Soc., Dalton Trans., 1999, 1201.

4 K. Shimojo, K. Kurahashi and H. Naganawa, Dalton Trans., 2008, 5083.

5 A. P. Abbott, G. Frisch, J. Hartley and K. S. Ryder, Green Chem., 2011, 13, 471.

6 C. H. C. Janssen, N. A. Macias-Ruvalcaba, M. AguilarMartinez and M. N. Kobrak, Int. Rev. Phys. Chem., 2015, 34, 591.

7 D. Dupont, D. Depuydt and K. Binnemans, J. Phys. Chem. B, 2015, 119, 6747.

8 Y. Wang, C. Huang, F. Li, Y. Dong, Z. Zhao and X. Sun, Sep. Purif. Technol., 2016, 162, 106.

9 A. Rout and K. Binnemans, Dalton Trans., 2014, 43, 1862.
10 S. Panja, R. Ruhela, S. C. Tripathi, P. S. Dhami, A. K. Singh and P. M. Gandhi, Sep. Purif. Technol., 2015, 151, 139.

11 M. L. Dietz and D. C. Stepinski, Talanta, 2008, 75, 598.

12 A. Rout, K. A. Venkatesan, T. G. Srinivasan and P. R. Vasudeva Rao, J. Hazard. Mater., 2012, 221-222, 62.

13 Y. Shen, W. Li, J. Wu, S. Li, H. Luo, S. Dai and W. Wu, Dalton Trans., 2014, 43, 10023.

14 C. Gaillard, V. Mazan, S. Georg, O. Klimchuk, M. Sypula, I. Billard, R. Schurhammer and G. Wipff, Phys. Chem. Chem. Phys., 2012, 14, 5187.

15 V. Mazan, I. Billard and N. Papaiconomou, RSC Adv., 2014, 4, 13371.

16 P. R. Vasudeva Rao, K. A. Venkatesan, A. Rout, T. G. Srinivasan and K. Nagarajan, Sep. Sci. Technol., 2012, 47, 204.

17 X. Sun, H. Luo and S. Dai, Chem. Rev., 2012, 112, 2100.

18 I. Billard, A. Ouadi and C. Gaillard, Anal. Bioanal. Chem., 2011, 400, 1555.

19 L. Y. Yuan, M. Sun, X. H. Liao, Y. L. Zhao, Z. F. Chai and W. Q. Shi, Sci. China: Chem., 2014, 57, 1432.

20 P. K. Mohapatra, D. R. Raut and A. Sengupta, Sep. Purif. Technol., 2014, 133, 69.

21 A. Rout, K. A. Venkatesan, T. G. Srinivasan and P. R. Vasudeva Rao, Radiochim. Acta, 2010, 98, 459.

22 M. S. Murali, N. Bonville and G. R. Choppin, Solvent Extr. Ion Exch., 2010, 28, 495.

23 I. Billard, A. Ouadi, E. Jobin, J. Champion, C. Gaillard and S. Georg, Solvent Extr. Ion Exch., 2011, 29, 577.

24 S. Panja, P. K. Mohapatra, S. C. Tripathi, P. M. Gandhi and P. Janardan, Sep. Purif. Technol., 2012, 96, 289.

25 C. Cuillerdier, C. Musikas, P. Hoel, L. Nigond and X. Vitart, Sep. Sci. Technol., 1991, 26, 1229.

26 L. Nigond, C. Musikas and C. Cuillerdier, Solvent Extr. Ion Exch., 1994, 12, 297.

27 G. J. Lumetta, B. K. McNamara, B. M. Rapko, R. L. Sell, R. D. Rogers, G. Broker and J. E. Hutchinson, Inorg. Chim. Acta, 2000, 309, 103.

28 Q. Tian and M. A. Hughes, Hydrometallurgy, 1994, 36, 315.

29 L. Nigond, C. Musikas and C. Cuillerdier, Solvent Extr. Ion Exch., 1994, 12, 261.

30 C. Musikas and G. Thiollet, Meeting of the American Chemical Society, Dallas, April 1989, p. 1989.

31 C. Musikas, Sep. Sci. Technol., 1988, 23, 1211.

32 T. Nakamura and C. Miyake, Solvent Extr. Ion Exch., 1995, 13, 253.

33 A. B. Patil, P. Pathak, V. S. Shinde, S. V. Godbole and P. K. Mohapatra, Dalton Trans., 2013, 42, 1519.

34 M. Bonnaffé-Moity, A. Ouadi, V. Mazan, S. Miroshnichenko, D. Ternova, S. Georg, M. Sypula, C. Gaillard and I. Billard, Dalton Trans., 2012, 41, 7526.

35 S. Georg, I. Billard, A. Ouadi, C. Gaillard, L. Petitjean, M. Picquet and V. Solov'ev, J. Phys. Chem. B, 2010, 114, 4276.

36 B. Ravel and M. Newville, J. Synchrotron Radiat., 2005, 12, 537.

37 M. Newville, B. Ravel, D. Haskel, J. J. Rehr, A. Stern and Y. Yacoby, Phys. B, 1995, 208-209, 154.

38 J. J. Rehr and R. C. Albers, Rev. Mod. Phys., 2000, 72, 621. 
39 I. Billard, A. Ouadi and C. Gaillard, Dalton Trans., 2013, 42, 6203.

40 A. Ikeda, C. Hennig, A. Rossberg, S. Tsushima, A. C. Scheinost and G. Bernhard, Anal. Chem., 2008, 80, 1102.

41 C. Görller-Wallrand and S. De Jaegere, J. Chim. Phys. Phys.Chim. Biol., 1972, 4, 726.

42 S. Wahu, J.-C. Berthet, P. Thuery, D. Guillaumont, M. Ephritikhine, R. Guillot, G. Cote and C. Bresson, Eur. J. Inorg. Chem., 2012, 3747.

43 D. Ternova, M. Boltoeva, L. Cointeaux, C. Gaillard, V. Kalchenko, V. Mazan, S. Miroshnichenko, P. K. Mohapatra, A. Ouadi, N. Papaiconomou, M. Petrova and I. Billard, J. Phys. Chem. B, 2016.
44 A. Ruas, P. Pochon, J.-P. Simonin and P. Moisy, Dalton Trans., 2010, 39, 10148.

45 S. Katsuta, Y. Watanabe, Y. Araki and Y. Kudo, ACS Sustainable Chem. Eng., 2016, 4, 564.

46 J. Foropoulos and D. D. DesMarteau, Inorg. Chem., 1984, 23, 3720.

47 M. L. Dietz, J. A. Dzielawa, I. Laszak, B. A. Young and M. P. Jensen, Green Chem., 2003, 5, 682.

48 M. L. Dietz and D. C. Stepinski, Green Chem., 2005, 7, 747.

49 C. H. C. Janssen, A. Sanchez and M. N. Kobrak, ChemPhysChem, 2014, 15, 3536. 